\title{
PERANCANGAN FLYER DAN BANNER SEBAGAI MEDIA PENDUKUNG SOSIALISASI KEGIATAN FAMILY DEVELOPMENT SESSION PROGRAM KELUARGA HARAPAN KECAMATAN SUKMAJAYA
}

\author{
Dian Handayani ${ }^{1}$, Ariefika Listya ${ }^{2}$, Puri Kurniasih ${ }^{3}$
}

Program Studi Desain Komunikasi Visual, Fakultas Bahasa dan Seni Universitas Indraprasta PGRI

\begin{abstract}
Abstrak
Flyer dan Banner merupakan media visual yang banyak digunakan dalam kegiatan sosialisasi atau penyuluhan. Peserta FDS PKH akan lebih mudah menangkap materi penyuluhan apabila mereka mengetahui point-point penting apa saja yang terdapat dalam materi yang disampaikan. Pembahasan dalam laporan kegiatan Pengabdian kepada Masyarakat ini menjabarkan tentang kegiatan Family Development Session (FDS) yang berlangsung di Kecamatan Sukmajaya. Maka, untuk mendukung kegiatan tersebut, dibutuhkan media visual yang dapat membantu berlangsungnya penyuluhan dalam rangka turut menyukseskan program FDS. Flyer yang dirancang berukuran A5 dengan bahan kertas stiker yang dapat ditempel di rumah peserta, sehingga peserta mudah membacanya ketika berlalu-lalang di rumah dan dapat mengingat materi penyuluhan. Sementara banner dirancang berukuran $60 \mathrm{~cm} \times 160 \mathrm{~cm}$ yang digunakan sebagai media sosialisasi. Banner diserahkan kepada pendamping PKH di Kecamatan Sukmajaya dan flyer langsung dibagikan kepada para peserta FDS setelah penyuluhan selesai. Pendamping PKH yang sekaligus sebagai mentor FDS sangat antusias dan berterima kasih atas banner yang kami berikan, karena mempermudah mereka dalam melakukan penyuluhan begitupun peserta PKH. Hasil kegiatan ini menunjukkan bahwa tujuan kegiatan terlaksana dengan baik dan pihak mitra pun sangat mengapresiasi.
\end{abstract}

Keywords: Flyer, Banner, Program Keluarga Harapan (PKH), Family Development Session (FDS)'

\begin{abstract}
Flyers and Banners are visual media that are widely used in socialization or counseling activities. PKH (Program Keluarga Harapan) FDS participants will be easier to understand if they know the key points of the counseling material which is presented. The discussion in this report paper of pengabdian kepada Masyarakat (community Service) outline the Family Development Session (FDS) activities that took place in Sukmajaya District. Visual media are needed to support the counseling in order to succeed the FDS program. Flyers are in A5 size, printed on sticker paper material that can be posted on each participant's house, so that they can easily read and remember the counseling material when walking around the house. The Banner sizes are $60 \mathrm{~cm}$ width $x 160 \mathrm{~cm}$ height which is used as a media for socialization. Banner were handed over to PKH facilitators in Sukmajaya District and flyers were immediately distributed to FDS participants after counseling was completed. PKH assistants who were also as FDS mentors were very enthusiastic and grateful for the banner, because it easier for them to conduct counseling as well as PKH participants. The results of this activity showed that the objectives were well implemented and the partners were very appreciative.
\end{abstract}

Keywords: Flyer, Banner, The family of hope program, Family Development Session (FDS)

Correspondence author: Dian Handayani, dian.zulaikhasaja@gmail.com, Jakarta, Indonesia 


\section{PENDAHULUAN}

Program Keluarga Harapan $(\mathrm{PKH})$ merupakan program bantuan tunai bersyarat yang diberikan kepada Keluarga Penerima Manfaat (KPM). Pemerintah Indonesia telah melakukan program PKH sejak tahun 2007 sebagai upaya percepatan penanggulangan kemiskinan, Program Perlindungan Sosial yang juga dikenal di dunia internasional dengan istilah Conditional Cash Transfers (CCT) ini terbukti cukup berhasil dalam menanggulangi kemiskinan yang dihadapi negara-negara berkembang, terutama masalah kemiskinan. Sebagai sebuah program bantuan sosial bersyarat, PKH membuka akses keluarga miskin terutama ibu hamil dan anak untuk memanfaatkan berbagai fasilitas layanan kesehatan (faskes) dan fasilitas layanan pendidikan (fasdik) yang tersedia di sekitar tempat tinggal mereka. Manfaat PKH juga mulai didorong untuk mencakup penyandang disabilitas dan lanjut usia dengan mempertahankan taraf kesejahteraan sosialnya sesuai dengan amanat konstitusi. Peserta PKH harus terdaftar dan hadir pada fasilitas kesehatan dan pendidikan terdekat.

Pada Program Keluarga Harapan terdapat sistem pendampingan kepada penerima bantuan. Proses dimulainya pelaksanaan Program Keluarga Harapan di tiap kota berbedabeda. Depok merupakan salah satu kota yang memulai Program Keluarga Harapan pada tahun 2014. Saat ini Program Keluarga Harapan tersebar di 11 kecamatan di Kota Depok yaitu kecamatan Sukmajaya, Pancoran Mas, Cimanggis, Cilodong, Cipayung, Limo, Beji, Tapos, Cinere, Sawangan dan Bojongsari.

Dalam mencapai target dan sasaran Program Keluarga Harapan yaitu terjadinya perubahan pola pikir dan perubahan perilaku bagi para penerima bantuan PKH, pemerintah mewajibkan para penerima bantuan tersebut mengikuti program Family Development Session atau lebih sering disingkat FDS merupakan sebuah inovasi baru yang telah di rancang dan dikembangkan oleh Kementerian Sosial Republik Indonesia bekerjasama dengan Bank Dunia khusus umtuk Program Keluarga Harapan (PKH). Kegiatan ini merupakan sebuah pengembangan atau penyempurnaan dari pertemuan kelompok Keluarga Penerima Manfaat PKH atau sering disebut P2K2 Pertemuan Peningkatan Kemampuan Keluarga.

Pada kegiatan FDS atau P2K2 peserta PKH akan menerima materi-materi yang berkaitan pengasuhan anak, pendidikan, kesehatan, perekonomian keluarga dan kesejahteraan sosial. Pendamping PKH-lah yang memberikan materi FDS pada setiap kegiatan, tentu setelah dibekali dengan pelatihan tentang FDS.

Dalam kegiatan ini Tim Abdimas fokus pada satu materi yang berkaitan dengan pengasuhan anak. Dalam setiap kegiatan FDS pendamping dibekali modul, salah satunya "Modul Pengasuhan dan Pendidikan Anak". Modul tersebut adalah hasil kompilasi berbagai penelitian yang ada serta observasi selama kunjungan lapangan dan uji coba ke lapangan oleh tim peneliti. P2K2 adalah sebuah inisiatif yang disusun bersama oleh Kementrian Sosial, Badan Perencanaan Pembangunan Nasional (Bappenas), Tim Nasional Percepatan Penanggulangan Kemiskinan (TNP2K), Bank Dunia dan Unicef (Wijasmara, 2014:1).

Pada kegiatan FDS terdapat interaksi antar pendamping $\mathrm{PKH}$ dengan peserta $\mathrm{PKH}$, yang bertujuan untuk membangun sebuah kepercayaan diri pada peserta dalam upaya menjadi orang tua yang lebih baik untuk keluarga mereka. Selain itu juga interaksi dua arah ini bisa menjadi saling tukar pengalaman atau sharing dalam pola pengasuhan anak antar peserta sehingga dapat diambil sebuah pengalaman yang baik untuk diterapkan dalam lingkungan keluarga masing-masing. Salah satu modul dalam FDS adalah Modul 
Pendidikan dan Pengasuhan Anak merupakan hasil kerjasama dari Kementerian Sosial RI dengan Bank Dunia (World Bank).

Mitra adalah masyarakat yang masuk ke dalam Program Keluarga Harapan (PKH) yang merupakan salah satu program dari Kementrian Sosial. Jika dipersempit lagi mitra adalah peserta PKH yang khususnya berada Kecamatan Sukmajaya Kota Depok. Salah satu bantuan PKH adalah fasilitas layanan pendidikan (fasdik), diantaranya berupa pemberian dana pendidikan. Program tersebut sangat membantu secara finansial, namun belum dapat mengubah pola dan perilaku masyarakat dalam memanfaatkan dana bantuan.

FDS adalah suatu kegiatan yang wajib diikuti oleh para penerima bantuan $\mathrm{PKH}$ yang sebagian besar adalah ibu-ibu, berupa Pertemuan Peningkatan Kemampuan Kapasitas Keluarga (P2K2). Materi dalam FDS sudah dirancang sedemikian rupa sehingga pesan perubahan agar tersampaikan. FDS dilaksanakan setiap satu bulan sekali dalam kegiatan pertemuan kelompok warga. Dalam kegiatan FDS yang peserta sebagian besar adalah ibu rumah tangga dibekali buku pintar, misalnya dalam modul 1 peserta dibekali buku pintar pengasuhan dan pendidikan anak. Hanya saja beberapa hal yang penting dalam materi yang disampaikan tidak ada dalam buku pintar tersebut. Tidak adanya point-point penting dalam buku pintar yang ibu-ibu terima, menyebabkan peserta PKH hanya mendengarkan pesan secara verbal dan pesan kurang tersampaikan.

Berdasarkan wawancara dan observasi awal yang tim abdimas lakukan, peserta saat ditanya kembali materi yang disampaikan kurang dapat memahami dan menyimpulkan materi yang telah disampaikan. Padahal sasaran target perubahan pola pikir dan perubahan perilaku bagi pada penerima bantuan terdapat pada point penting tersebut. Permasalahan selanjutnya adalah selama proses kegiatan FDS tidak ada media yang dapat dilihat pendukung proses kegiatan FDS, misalnya $x$-banner atau spanduk yang berisi tentang materi yang akan diberikan. Padahal media merupakan alat yang digunakan untuk mempermudah dalam membelajarkan, dapat berupa buku, modul, selebaran, majalah, animasi, rekaman video atau audio, dan fasilitas sumber belajar yang lainnya. Seiring perkembangan, media saat ini mengarah ke berbasis komputer, misalnya materi sudah dalam bentuk multimedia (Mayer, 2009:3)

Berdasar permasalah mitra setelah observasi dan wawancara awal, tim abdimas menawarkan solusi: pertama kami akan merancang flayer yang berisi point penting yang akan mudah diingat yang berdampak pada perubahan pola pikir dan perilaku para penerima bantuan. 7 hal penting menjadi orang tua yang lebih baik dirancang dalam media flyer yang akan dibagikan saat kegiatan FDS agar apa yang telah dijelaskan oleh penyuluh dapat diingat dan dipraktekkan dalam kehidupan sehari-sehari. Flyer dibuat dengan ukuran A5 dengan bahan kertas stiker agar dapat ditempel di rumah peserta. Tujuannya supaya materi yang disampaikan dibaca oleh suami dan anak peserta PKH, karena akan sangat membantu perubahan dengan lebih baik. Selain itu, tim abdimas juga merancang banner ukuran $60 \mathrm{~cm}$ x $160 \mathrm{~cm}$ yang digunakan sebagai media sosialisasi agar saat kegiatan penyuluhan berlangsung, peserta sambil mendengarkan penyuluhan mereka juga akan memperhatikan banner yang akan di letakkan di hadapan peserta selama penyuluhan berlangsung.

Ukuran standar flyer menurut Frasie (2017: 120-121) terbagi dua, yaitu ukuran Eropa dan ukuran Amerika. Ukuran Eropa diantaranya A7 (74 mm x 105 mm), A6 (105 mm x $148 \mathrm{~mm})$, DL (99 mm x $210 \mathrm{~mm})$, A5 (148 mm x $210 \mathrm{~mm})$ dan A4 (210 mm x 297 mm). Ukuran Amerika yakni, 4.25 inchi x 5.5 inchi, 5.5 inchi x 8.5 inchi, 6 inchi x 9.5 inchi, 8.5 inchi x 11 inchi, 8.5 inchi x 17 inchi, 8.5 inchi x 14 inchi, dan 4. 25 inchi x 11 inchi. Banner adalah tanda berukuran besar yang menyampaikan pesan sederhana. 
Ukuran dan orientasi banner beragam tergantung ruang yang tersedia dan jarak baca yang dituju agar terbaca oleh audiens. Teks harus pendek dan langsung kepada intinya (to the point) (Graham, 2011: 268)

\section{METODE PELAKSANAAN}

Waktu kegiatan mulai dari perencanaan, persiapan, pelaksanaan, hingga penyusunan laporan berlangsung mulai dari September sampai dengan November 2018. Pelaksanaan pembagian flyer dan penyerahan banner pada kegiatan FDS dilaksanakan pada Jumat 19 Oktober 2018 pukul 15.00 WIB. Lokasi kegiatan berlangsung di salah satu rumah peserta PKH di lingkungan Kecamatan Sukmajaya.

Karena permasalahan yang dihadapi oleh mitra adalah kurang adanya media pendukung dalam sosialiasi kegiatan FDS. Dan kami mempunyai ide untuk membantu proses kegiatan FDS agar berjalan lancar dan proses kegiatan FDS dapat mencapai tujuan dan sasaran kegiatan, yaitu terjadi perubahan pola pikir dan perubahan perilaku bagi peserta PKH. Langkah pertama yang akan dilakukan adalah mencari referensi tentang pengasukan dan pendidikan yang terdapat pada modul yang di terbitkan kemensos.

Pemahaman yang kami tawarkan adalah pemahaman mengenai media pendukung pada kegiatan yang akan dibungkus dengan visual yang kreatif dan menarik. Sehingga peserta PKH yang mengukuti kegiatan FDS akan lebih memahami materi yang akan disampaikan. Berikut prosedur kerja dan tahapan rencana kegiatan untuk mendukung realisasi kegiatan tersebut :

1. Observasi

Mengobservasi pada saat kegiatan FDS berlangsung

2. Pengumpulan dan pengolahan data

Mengumpulkan referensi buku-buku tentang modul pengasuhan dan pendidikan anak

3. Perancangan flayer dan $x$-banner

Merancang flayer dan $x$-banner yang sesuai dengan hasil referensi yang telah dikumpulkan.

4. Pencetakan flayer dan $x$-banner

Mencetak flayer dan $x$-banner yang telah dirancang

5. Membagikan flayer dan memasang $x$-banner saat kegiatan FDS

Membagikan flayer saat kegiatan FDS berlangsung dan memasang $x$-banner sebagai media pendukung FDS

6. Sosialisasi

Sosialisasi kepada pendamping dan peserta FDS tentang flayer dan banneryang telah dirancang

7. Dokumentasi

Selain data, juga mendokumentasikan aktivitas peserta pada saat pelaksanaan abdimas, berupa foto perancangan flayer dan $x$-banner, kegiatan sosialisasi dalam kegiatan FDS 


\section{Evaluasi}

Memeriksa semua agenda kegiatan dan mendiskusikan kembali apa saja kekurangan selama proses pelaksanaan abdimas untuk kemudian dapat dilaporkan baik kepada pihak mitra maupun kepada pihak LPPM.

\section{HASIL DAN PEMBAHASAN}

Sebelum penyuluhan dimulai, para peserta duduk berkumpul membentuk setengah lingkaran menghadap ke mentor.

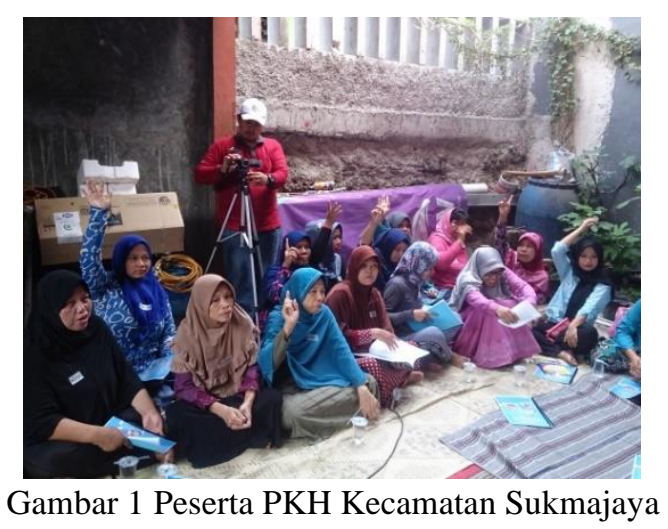

Program penyuluhan dimulai dengan perkenalan antara peserta dengan Tim Abdimas Dosen Desain Komunikasi Visual.

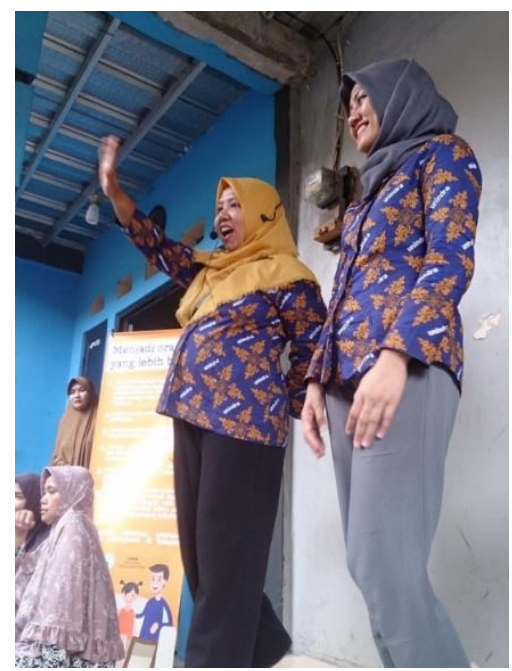

Gambar 2 Perkenalan Tim Dosen Abdimas DKV-Unindra

Pelaksanaan program penyuluhan telah didokumentasikan dalam bentuk video. Penyerahan banner dan pembagian flyer dilakukan setelah penyuluhan selesai. 


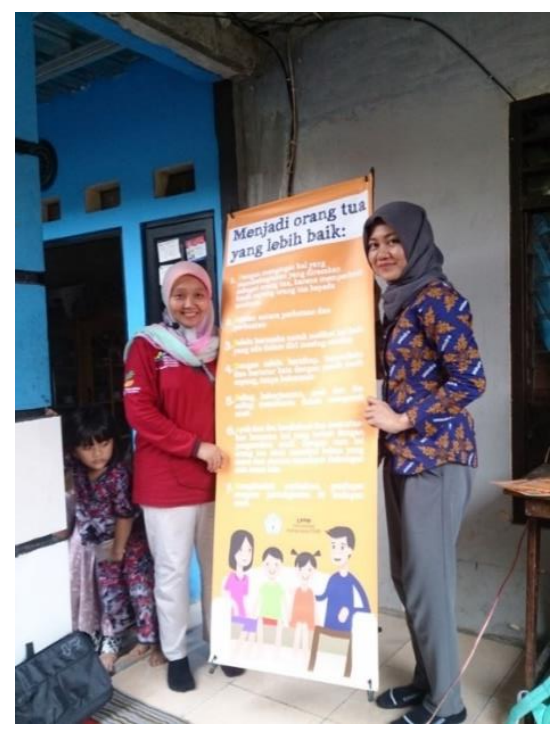

Gambar 3 Penyerahan Banner

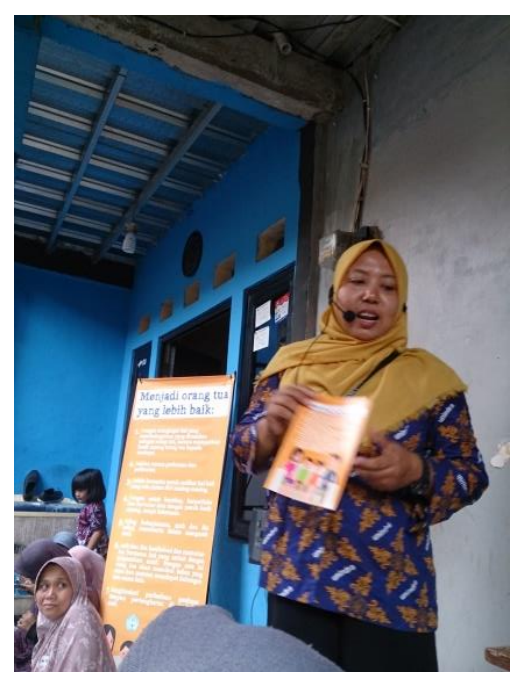

Gambar 4 Penjelasan poin-poin penting materi FDS dalam Flyer

Mitra merupakan masyarakat PKH di Kecamatan Sukmajaya Depok. Hasil luaran yang didapatkan dari pengabdian masyarakat ini adalah media visual berupa flyer dan banner yang diserahkan kepada pendamping PKH sekaligus mentor FDS dan peserta PKH Kecamatan Sukmajaya. Desain flyer dan banner telah dikonsepsikan dan dirancang sebelumnya berdasarkan kualifikasi dan kesepakatan tim abdimas.

Media visual tersebut telah diserahkan pada kegiatan penyuluhan yang berlangsung pada Jumat, 19 Oktober 2018 di salah satu rumah peserta PKH di wilayah Kecamatan Sukmajaya Depok. Proses kegiatan tersebut juga telah didokumentasikan menjadi sebuah video sebagai hasil luaran kegiatan.

Semoga pihak mitra dapat memanfaatkan media visual tersebut dengan baik, sehingga salah satu program sosial dari pemerintah ini menjadi semakin efektif. Tim kami berharap abdimas ini dapat membantu menyukseskan program tersebut, sehingga program tridarma perguruan tinggi dapat berjalan beriringan dengan program sosial dari pemerintah dalam rangka menyukseskan kehidupan bangsa pada ranah pendidikan. Hasil kegiatan menunjukkan bahwa media visual pendukung sosialisasi pada penyuluhan dapat bermanfaat bagi pihak. 


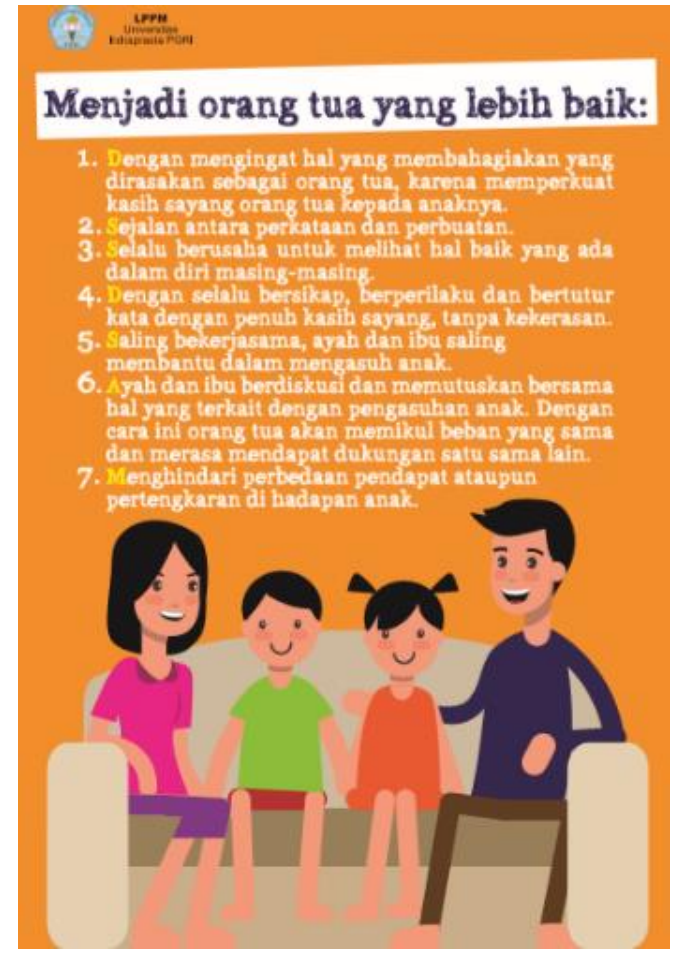

Gambar 5 Rancangan Flyer

\section{Menjadi orang tua yang lebih baik:}

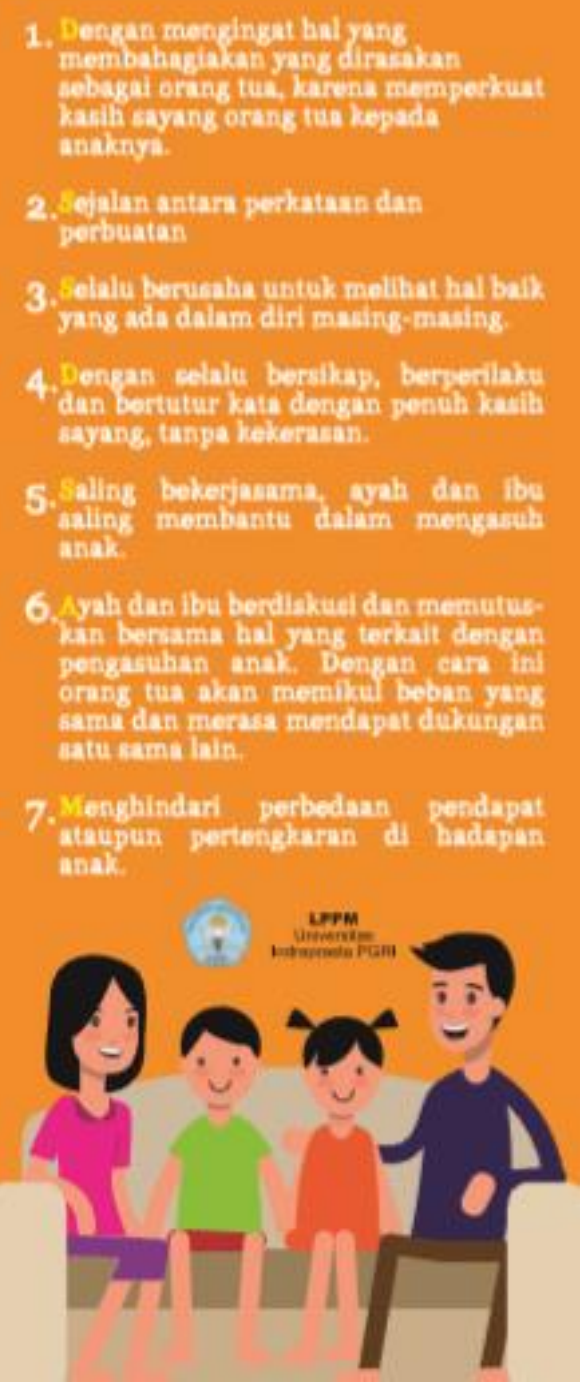

Gambar 6 Rancangan Banner

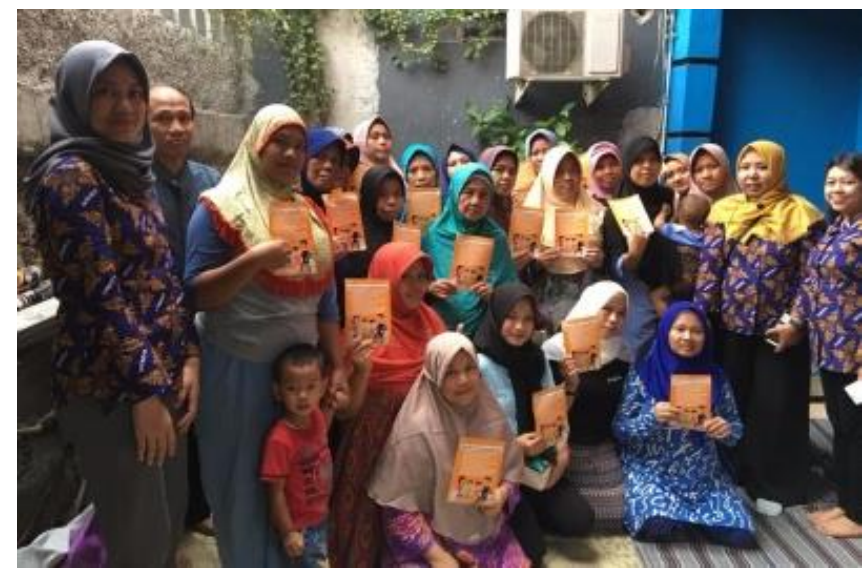

Gambar 7 Foto bersama dengan peserta FDS 


\section{SIMPULAN}

Flyer dan banner dapat menjadi media visual yang efektif untuk menyampaikan pesan pada program sosialisasi dalam penyuluhan. Flyer berupa stiker dengan ukuran A5 ternyata cukup menarik sebagai media sosialisasi yang mudah dibaca (ukuran tidak terlalu kecil) dan ditempatkan dimana saja (ukuran tidak terlalu besar), sehingga membantu dalam mengingat materi yang perlu dipraktikkan dalam keseharian para peserta PKH. Banner memang selalu mencuri perhatian sebagai media sosialisasi, hanya perlu menempatkannya secara strategis semua mata akan tertuju pada banner, dan secara tidak langsung orang akan mengamati serta membaca isi banner tersebut.

Sebuah program tidak selalu sempurna, dalam pelaksanaannya selalu saja ada kekurangan, begitu juga dengan PKH yang mempunyai agenda FDS pada tiap kecamatan di tiap kota di Indonesia. Mentor sudah dibekali beberapa buku panduan untuk melakukan penyuluhan, tapi ternyata buku panduan tersebut kurang cukup untuk melakukan penyuluhan yang efektif, karena materinya cukup padat dan banyak, sehingga perlu merangkum sendiri poin-poin yang perlu disampaikan, agar pesan dalam materi tersebut dapat tersampaikan dalam waktu yang terbatas. Dengan demikian, media visual berupa flyer dan banner yang berisi poin-poin penting dalam materi FDS sangat membantu mentor dan juga peserta dalam menyerap materi agar lebih mudah diingat dan dipraktikkan.

Program Studi Desain Komunikasi Visual Unindra PGRI dapat terus berpartisipasi mengembangkan inspirasi bagi masyarakat dan ikut mendukung memajukan usaha pemerintah di bidang pendidikan. Kegiatan ini merupakan bentuk perwujudan moto meningkatkan kepedulian dan kreativitas di bidang pendidikan sebagai bagian Tridarma Perguruan Tinggi. Program pengabdian kepada masyarakat tidak harus selalu bediri sendiri sebagai program khusus perguruan tinggi. Menurut kami, kita juga dapat menjadi penyokong bagi program lain, terutama program pemerintah yang sedang berjalan agar supaya program tersebut dapat berjalan lebih efektif. Dengan demikian, kami menyarankan lebih banyak lagi tim program pengabdian kepada masyarakat di perguruan tinggi dapat bekerja sama dan berjalan beriringan dengan program lainnya yang terkait.

\section{DAFTAR PUSTAKA}

Frasie, R. (2017). Graphic design handbook. Sibiu: independently published.

Graham, L. (2011). Basic of design: Layout \& tipography for beginners, Second edition. New York: Delmar Cengange Learning.

https://pkh.kemsos.go.id/tentang-pkh/apa-itu-pkh

http://keluargaharapan.com/menumbuhkan-harapan-bersama-family-developmentsession-pkh/

Mayer, R. I. (2009). Multi-Media Learning: Prinsip-Prinsip dan Aplikasi. Diterjemahkan Teguh Wahyu Utomo. Yogyakarta: Pustaka Pelajar.

Wijasmara, F (2014). Modul Pengasuhan dan Pendidikan Anak. Jakarta 